\section{NEW METHOD FOR IDEAL CROWN ATTACHMENT}

Researchers at Chalmers University of Technology in Sweden are developing a method for determining exactly how a tooth should be ground down in order to attach a dental crown to it. The method is expected to result in significantly cheaper and faster treatment, with reduced risks of patients having problems with their crowns.

The task of preparing a tooth for the attachment of a crown is dependent on the individual dentist's eye and skill but soon dentists will be able to benefit from a computer program being produced by a group of researchers at Chalmers, at the initiative of Nobel Biocare. The researchers are now planning to run clinical tests.

'In our software, you can feed in the existing tooth's measurements, done by laser scanning the tooth,' said Evan Shellshear, Chalmers researcher. 'The software then calculates how much of that tooth should be ground down, and the output is a 3D model of the optimal shape of the tooth. You can also get a 3D animation showing precise suggestions for manoeuvring the grinding tool in order to achieve the objective without colliding with the teeth or mouth parts.'

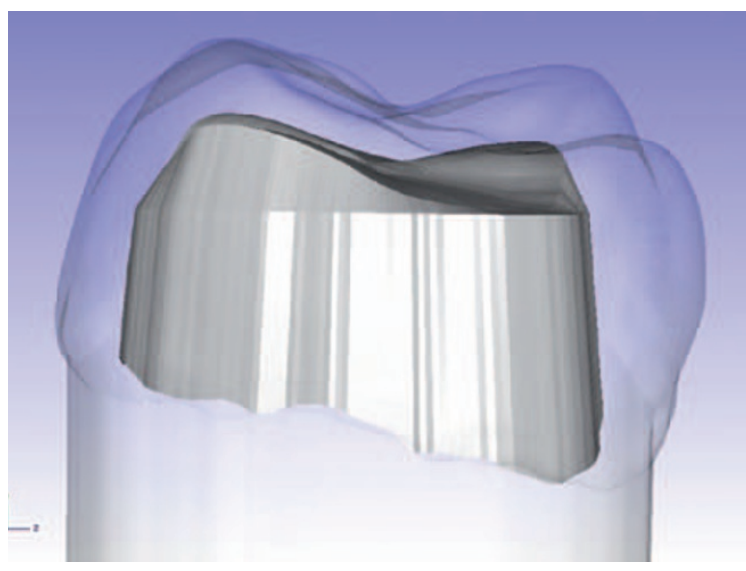

Visualisation of a tooth showing the optimum shape that should remain after the tooth has been ground down in order to be fitted with an artificial dental crown

\section{SUPPORT PENSIONS ACTION DAY}

The British Dental Association (BDA) is urging dentists to support the wider health and public sector on a day of action against government proposals to downgrade their pensions.

The BDA is one of a number of professional representative bodies in the health sector whose members are not striking, but it is nevertheless encouraging members to demonstrate opposition to the Government plans by participating in the day of action on 30 November.

Members in general practice are urged to display in their practices an A3-sized poster (pictured bottom right) enclosed with this issue of the $B D J$. The poster makes clear that a decision by dentists not to strike on 30 November should not be misinterpreted as agreement with the proposed changes to pensions. The poster reflects the friendly and approachable character of the profession, while explaining to patients that dentists are as unhappy as other public sector colleagues with what the Government is proposing. Associates should discuss practice policy on displaying such posters with the practice owner(s).

Members in salaried primary care or hospital services should not display the poster on NHS premises. Instead, they should check with workplace representatives whether events are being organised to mark the day of action and participate in those.

The BDA is also encouraging all members to share their participation in the day on Twitter, by posting a photograph of the poster on display at their practice or promoting their participation in a workplace event and adding the hash tag \#30nov to their tweet.

Dentists can also add weight to the campaign by signing a Government e-petition and contacting their MP directly, supplementing the direct lobbying work the BDA has already done on their behalf. Full details of the campaign and how dentists can add their voices to it are available at: www. bda.org/protectNHSpensions.

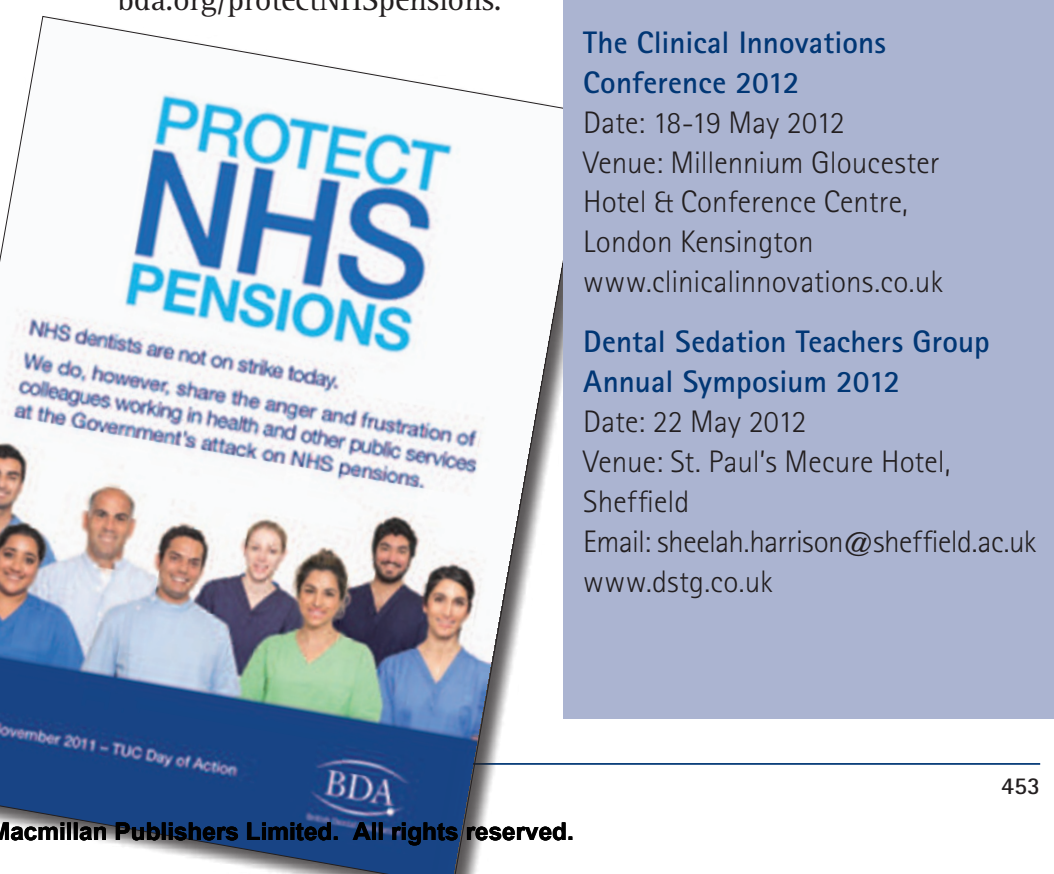

Email:wfld2012@kenes.com

\section{DIARY}

2012

NHS North Western Deanery:

Safeguarding children

(child protection) Level 2

Date: 24 January 2012

Venue: North Western Deanery,

Manchester

http://www.badt.org.uk/events/

downloads/7.pdf

UCL Eastman Dental Institute:

Career opportunities in UK dentistry

Date: 3 February 2012

Venue: Hotel Russell, London

Telephone: 02079051261

Email:k.rhatigan@eastman.ucl.ac.uk

BDA Events: Setting up in practice: how to succeed in challenging times Date: 9 March 2012

Location: Leeds

Telephone: 02075634590

(quote 'SUIP1'to book a second

place half price)

13th Congress of the World

Federation of Laser Dentistry

Date: 26-28 April 2012

Location: Barcelona

www.wfld-barcelona2012.com

British Dental Conference

and Exhibition 2012

Date: 26-28 April 2012

Venue: Manchester Central

Convention Complex

www.bda.org/conference

Excellence in Dentistry

2012 Conference

Date: 26-29 April 2012

Location: Istanbul

www.excellence-in-dentistry.org

The Clinical Innovations

Conference 2012

Date: 18-19 May 2012

enue: Millennium Gloucester

Hotel \& Conference Centre,

London Kensington

Dental Sedation Teachers Group

Annual Symposium 2012

Date: 22 May 2012

Venue: St. Paul's Mecure Hotel,

Sheffield

Email:sheelah.harrison@sheffield.ac.uk

www.dstg.co.uk 